\title{
THE PRESERVATION OF URINE SPECIMENS FOR DELAYED BACTERIOLOGICAL EXAMINATION
}

\author{
D. GOODE, F.I.M.L.T., L.I.Biol. \\ Senior Experimental Officer, Royal Army Medical College
}

\begin{abstract}
SUMMARY: A trial to determine a suitable method of preserving specimens of urine for delayed bacteriological examination is described. The results are discussed and the use of 1.8 per cent boric acid is recommended.
\end{abstract}

\section{Introduction}

The investigation of suspected bacilluria often presents technical difficulties even in the well equipped hospital, because bacteriological examination, if it is to be reliable, requires the specimen to be dealt with by the laboratory staff as soon as possible after voiding. In practice this usually means that the patient of a small medical unit without laboratory facilities has either to be sent to the nearest hospital or the specimen taken to the laboratory. When the specimen can be dealt with within the hour or refrigerated for short periods no problem arises, occasionally however the only way the specimen can be delivered is by post with consequent delay of a day or more. Under such circumstances the results can rarely be relied upon.

Since the work of Kass (1956) gave significance to bacterial counts per ml of midstream urine specimens, a number of attempts have been made to devise a method of preventing the multiplication of organisms in such specimens whilst they are in transit to the laboratory.

It was therefore decided to examine by a viable count technique a number of methods for the preservation of urine. Initially the use of Stuart's transport medium was considered, $5 \mathrm{ml}$ of urine being added to a 'Universal container' which was then filled to the brim with the transport medium. This had been modified by increasing by one fifth all chemicals in the formula (to compensate for urine added) and the reduction of agar concentration. Viability studies showed that within twenty-four hours increases ranging from 10 fold to 1,000 fold occurred (P. D. Meers and D. Goode unpublished).

Odegaard (1967) suggested the use of 10 per cent Edathamil Calcium Disodium (E.D.T.A.) and stated that a satisfactory bacteriostatic action was obtained when using strains of Escherichia coli, Proteus mirabilis and Pseudomonas aeruginosa.

It had been previously suggested that the effect of E.D.T.A. was bacteriocidal (MacGregor and Elliker 1958), also that it was bacteriostatic (Zemjanis and Hoyt 1960). Gray and Wilkinson (1965) by studying the action of E.D.T.A. on isolated cell wall suspensions concluded that the action of E.D.T.A. appeared to involve the removal or displacement of a metal cation from the cell wall, causing leakage of cell solutes and loss of viability.

Porter and Brodie (1969) recommended the use of 1.8 per cent boric acid as a preservative in urine where specimens are to be sent through the post. In a trial involving 130 specimens this method was compared with dip-inoculation slide transport medium. The method of preservation by boric acid was found convenient and satisfactory. 
While Gray and Wilkinson (1965) suggest that E.D.T.A. may well eventually sterilize suspensions on standing, it was thought that preservation by E.D.T.A. at 10 per cent concentration would provide a useful comparative assessment of preservation by 1.8 per cent boric acid.

\section{Design of the trial}

Urine was obtained as a mid-stream specimen from healthy volunteers and inoculated with sufficient of an overnight culture to give an anticipated viable count of between 100,000 per $\mathrm{ml}$ and $1 \times 10^{6}$ per $\mathrm{ml}$.

The specimen was then distributed in $100 \mathrm{ml}$ amounts into three sterile bottles. The first having no preservative, the second with $10 \mathrm{~g}$ E.D.T.A. and the third with $1.8 \mathrm{~g}$ of boric acid. Further experiments were carried out with the specimens added to plastic Universal containers with the same preservatives. The bottles were well shaken to dissolve the chemicals; E.D.T.A. it was found, took some appreciable time to dissolve completely.

A viable count by the technique of Miles and Misra (1938) was carried out on the untreated specimen to obtain a base line figure.

Viable counts were further carried out at 4, 18, 24 and 48 hours from the start. The medium used throughout was MacConkey's bile salt agar.

The findings from preliminary experiments showed that the well known nutrient properties of healthy urine as a culture medium, allowed the count of untreated specimens to rise rapidly in the first four hours at room temperature and to continue this rise to a point where $300 \times 10^{6}$ viable organisms per $\mathrm{ml}$ were present after twenty-four hours. When untreated specimens were becoming visibly turbid to the naked eye after a few hours standing at room temperature no counts were performed, only check plating to establish that the increase in turbidity was due to the organism originally introduced.

Due to the number of viable counts involved, it was also decided that information of viability at 24 and 48 hours would be of the greatest value and the examination at other points was discontinued.

Traum and Hart (1916) in a study of preservation of milk by boric acid showed that tubercle bacilli were not destroyed. A very limited series of experiments were therefore conducted with urine artificially infected with tubercle bacilli ( $\mathrm{H} .37 \mathrm{Rv})$. Portions from such specimens were stored at room temperature for seven day periods, both with and without the addition of 1.8 per cent boric acid as a preservative. Concentrations by the method of Petroff ( 4 per cent $\mathrm{NaOH}$ ) were carried out on all specimens, and cultures made on Lowenstein-Jensen medium.

Consideration was also given during the trial to the possibility of using the $1 \mathrm{oz}$ $(28 \mathrm{ml})$ Universal container, produced in plastic with a conical shaping to the inside of the base, as a convenient dispensing measure for the boric acid crystals. It was thought that filling this conical depression at the base of the container level with crystals might give an approximately correct amount of the chemical.

Twenty containers were taken and dry boric acid added to the level of the top of the conical depression. The contents of the twenty containers were then weighed individually and all were found to be about $1.0 \mathrm{~g}$ (lowest weight $0.82 \mathrm{~g}$, highest $1.15 \mathrm{~g}$. Nine readings were over $1.0 \mathrm{~g}$.) This would have given concentrations of 4 per cent boric acid which is 
Table I

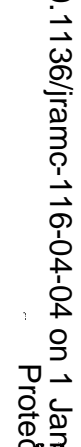

Comparison of viable counts of fresh urine inoculated with dilution of Escherichia coli faecal type I, with counts 然 角 same bulk infected sample preserved with boric acid 1.8 per cent or with 10 per cent E.D.T.A. Counts per $\mathrm{ml}$ of ' $\mathrm{nea}$ (र) urine.

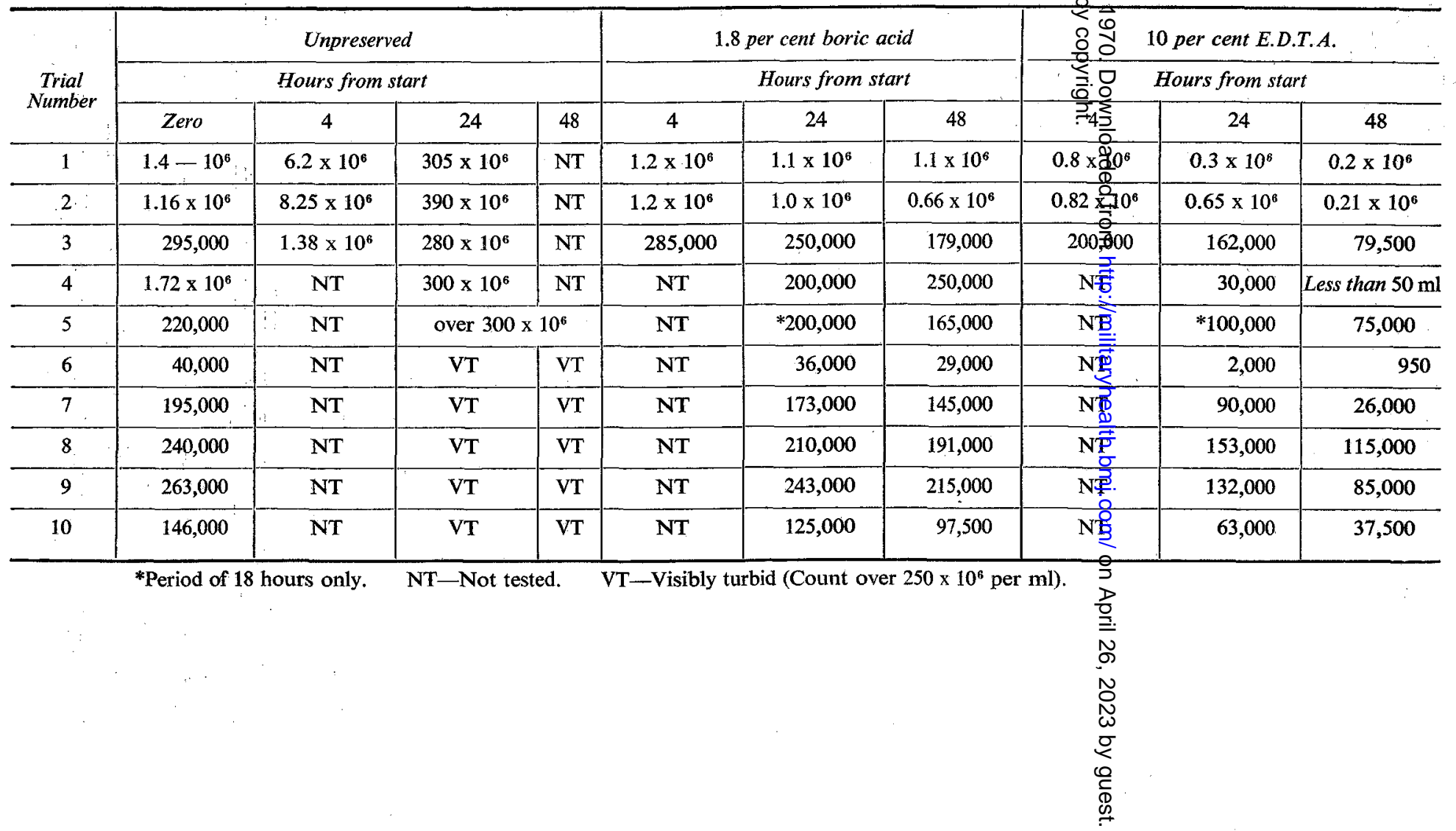


Table II

Bulk urine specimen inoculated with diluted suspension of Proteus mirabilis.

Samples compared-Unpreserved, preserved with 1.8 per cent boric acid, preserved with 10 pegिc른. E.D.T.A.

All counts are per $\mathrm{ml}$ of 'neat' urine.

\begin{tabular}{|c|c|c|c|c|c|c|}
\hline \multirow{3}{*}{$\underset{\text { Number }}{\text { Trial }}$} & \multicolumn{2}{|c|}{ Unpreserved } & \multicolumn{2}{|c|}{1.8 per cent boric acid } & \multicolumn{2}{|c|}{$\underbrace{\bar{\sigma}}_{0} \vec{\theta} \quad 10$ per cent E.D.T.A. } \\
\hline & \multicolumn{2}{|c|}{ Hours from start } & \multicolumn{2}{|c|}{ Hours from start } & \multicolumn{2}{|c|}{ Hours from start } \\
\hline & Zero & 18 & 18 & 48 & 을 익18 & 48 \\
\hline 1 & 500,000 & VT & 250,000 & 223,000 & $\overline{\mathbb{G}} 0,000$ & 125,000 \\
\hline 2 & 540,000 & VT & 495,000 & 430,000 & $\bar{B} 5,000$ & 35,000 \\
\hline 3 & 105,000 & VT & 91,000 & 55,500 & $\overline{\mathrm{g}}_{4}, 500$ & 15,000 \\
\hline 4 & 225,000 & $\mathrm{VT}$ & 197,500 & 184,000 & $\overline{\varnothing 0,500}$ & 32,000 \\
\hline 5 & 45,000 & †VT & $\uparrow 37,000$ & 31,000 & 0,500 & 3,000 \\
\hline 6 & 345,000 & VT & 250,000 & 198,500 & †䓞 8,000 & 71,000 \\
\hline 7 & 820,000 & VT & 755,000 & 690,000 & 侪7,000 & 61,000 \\
\hline 8 & 92,500 & VT & 84,000 & 75,000 & 笘7,000 & 15,100 \\
\hline 9 . & 76,500 & VT & 70,000 & 59,000 & $\bar{S}_{\dagger}^{\dagger} 5,450$ & 2,200 \\
\hline 10 & 235,000 & VT & 215,000 & 193,000 & $\frac{\text { † }}{3} 41,000$ & 99,000 \\
\hline
\end{tabular}


too high and the method is not recommended. A possible answer for suitable collection containers would be the use of a pharmaceutical powder dispensing machine set to deliver $0.5 \mathrm{~g}$ amounts of boric acid into Universal containers of $1 \mathrm{oz}(28 \mathrm{ml})$.

\section{Results}

No specimen preserved with boric acid failed to yield a positive culture, and several unpreserved specimens were overgrown with Bacillus species. Little significant variation occurred between counts obtained at the start of each experiment and those from specimens preserved for twenty-four hours with 1.8 per cent boric acid (Tables I to III). At concentrations of boric acid below 1.5 per cent a significant rise occurred in viable

\section{Table III}

Comparison of viable counts of fresh urine inoculated with a dilution of a culture of Streptoccus faecalis with counts of the same bulk specimen preserved with 1.8 per cent boric acid.

All counts are per ml of 'neat' urine.

\begin{tabular}{c|c|c|c|c|c}
\hline \multirow{2}{*}{$\begin{array}{c}\text { Experiment } \\
\text { number }\end{array}$} & \multicolumn{3}{|c|}{ Unpreserved } & \multicolumn{2}{c}{ Preserved with boric acid } \\
\cline { 2 - 6 } & Zero & 24 & 48 & 24 & 48 \\
\hline \multirow{2}{*}{1} & 151,000 & VT & VT & 134,000 & 125,000 \\
2 & 76,000 & VT & VT & 65,500 & 62,500 \\
3 & 305,000 & VT & VT & 350,000 & 325,000 \\
4 & 92,000 & VT & VT & 95,000 & 76,000 \\
5 & 490,000 & VT & VT & 425,000 & 400,000 \\
\hline
\end{tabular}

VT-_-Visibly turbid, count over $250 \times 10^{6}$ per ml (Routine plating carried out to confirm causative organism). E.D.T.A. was not compared in this small series of experiments.

Table IV

Effect of varying the concentration of boric acid used as a preservative.

A single bulk specimen was inoculated with a dilution of Escherichia coli. This was then distributed into a number of Universal containers in $\mathbf{2 5} \mathrm{ml}$ amounts and preserved with quantities of boric acid as shown Viable counts were carried out at 24 and 48 hours.

As counts per $\mathrm{ml}$ of 'neat' urine.

\begin{tabular}{|c|c|c|c|}
\hline & \multirow{2}{*}{$\begin{array}{l}\text { Concentration of } \\
\text { boric acid as } \\
\text { per cent }\end{array}$} & \multicolumn{2}{|c|}{ Viable count } \\
\hline & & 24 & 48 \\
\hline $\begin{array}{l}\text { Viable count of } \\
\text { untreated specimen } \\
275,000 \text { per ml at start } \\
\text { (heavy visible growth } \\
\text { after } 24 \text { hours at room } \\
\text { temperature) }\end{array}$ & $\begin{array}{l}1.0 \\
1.5 \\
2.0 \\
2.5 \\
3.0 \\
3.5 \\
4.0 \\
4.5 \\
5.0 \\
5.5 \\
6.0 \\
6.5 \\
7.0\end{array}$ & $\begin{array}{c}600,000 \\
304,000 \\
270,000 \\
240,000 \\
155,000 \\
75,000 \\
70,000 \\
22,500 \\
18,100 \\
5,000 \\
\text { No growth } \\
", \\
,\end{array}$ & $\begin{array}{c}1.1 \times 10^{6} \\
290,000 \\
285,000 \\
225,000 \\
132,000 \\
82,000 \\
67,000 \\
18,400 \\
14,200 \\
1,200 \\
\text { No growth } \\
\text { ", } \\
\text { " }\end{array}$ \\
\hline
\end{tabular}

No growth-No colonies obtained from $1 / 5$ th $\mathrm{ml}$ of a 1 in 10 dilution specimeni. 
organisms per $\mathrm{ml}$ while with concentrations below 2.5 per cent exerted a slowly progressive disinfectant action (Table IV).

A concentration of 2 per cent boric acid did not apparently prevent the recovery of Mycobacterium tuberculosis after seven days exposure in normal urine (Table V).

\section{Table V}

Preservation of Mycobacterium spp. in urine.

Bulk urine $600 \mathrm{ml}$ was inoculated with $5.0 \mathrm{ml}$ of saline into which had been suspended approximately $20 \mathrm{mg}$ of H.37 Rv strain of Mycobacterium tuberculosis.

The specimen was well mixed and distributed in $25 \mathrm{ml}$ portions into 20 Universal containers. These were kept on the bench in a warm room for seven days. Ten were preserved with 2 per cent boric acid, the remaining ten served as controls.

\begin{tabular}{cc|c|c}
\hline \multicolumn{2}{c|}{ Preserved with boric acid } & \multicolumn{2}{|c}{ Unpreserved } \\
\hline $1+$ & $6+$ & $1+$ & $6+$ \\
$2+$ & $7+$ & $2-$ & $7-$ \\
$3+$ & $8+$ & $3+$ & $8+$ \\
$4+$ & $9+$ & $4+$ & $9+$ \\
$5+$ & $10+$ & $5-$ & $10-$ \\
\hline
\end{tabular}

+ Positive culture obtained on Lowenstein-Jensen medium after concentration by Petroff's method.

- Lowenstein-Jensen medium showing marked change to deep green colour after a few days incubation and becoming overgrown with Bacillus spp. Mycobacterium tuberculosis not grown after eight weeks at $37^{\circ} \mathrm{C}$.

\section{Conclusions}

The use of 1.8 per cent boric acid would seem to be a most satisfactory and very economic method of preserving urine specimens at room temperature for over twentyfour hours. Such specimens taken for bacteriological examination, would give clinically acceptable results after an overnight delay in delivery to the laboratory.

Some basic dispensing problems are obvious in the issue of containers for the collection of specimens of urine to be preserved with 1.8 per cent boric acid and the use of a dispensing machine set to deliver $0.5 \mathrm{~g}$ amounts of the chemical is suggested for this purpose.

\section{REFERENCES}

GraY, G. W. and Wilkinson, S. G. (1965). J. appl. Bact. 29, 1153.

Kass, E. H. (1956). Trans. Ass. Amer. Phycns. 69, 56.

MACGregor, D. R. and Elliker, P. R. (1958). Canad. J. Microbiol. 4, 499.

Miles, A. A. and MisRa, S. S. (1938). J. Hyg. (Lond.). 38, 732.

ODEGAARD, K. (1967). Acta path. microbiol. scand. 71, 393.

Porter, I. A. and Brodie, J. (1969). Brit. med. J. ii, 353.

Zemianis, R. and HoYt, H. H. (1960). Amer. J. vet. Res. 21, 1066. 